\title{
Metabolomics to Diagnose Oxidative Stress in Perinatal Asphyxia: Towards a Non-Invasive Approach
}

\author{
Anne Lee Solevåg ${ }^{1, *(\mathbb{C})}$, Svetlana N. Zykova ${ }^{2}$, Per Medbøe Thorsby ${ }^{2}$ and Georg M. Schmölzer ${ }^{3,4}(\mathbb{C}$ \\ 1 The Department of Paediatric and Adolescent Medicine, Oslo University Hospital, 0424 Nydalen, Norway \\ 2 Biochemical Endocrinology and Metabolism Research Group, The Hormone Laboratory, Department of \\ Medical Biochemistry, Oslo University Hospital, 0424 Nydalen, Norway; svezyk@ous-hf.no (S.N.Z.); \\ pertho@ous-hf.no (P.M.T.) \\ 3 Centre for the Studies of Asphyxia and Resuscitation, Neonatal Research Unit, Royal Alexandra Hospital, \\ Edmonton, AB 23821, Canada; georg.schmoelzer@me.com \\ 4 Department of Pediatrics, Faculty of Medicine and Dentistry, University of Alberta, \\ Edmonton, AB 23821, Canada \\ * Correspondence: a.l.solevag@medisin.uio.no; Tel.: +47-4146-9314
}

Citation: Solevåg, A.L.; Zykova, S.N.; Thorsby, P.M.; Schmölzer, G.M.

Metabolomics to Diagnose Oxidative Stress in Perinatal Asphyxia: Towards a Non-Invasive Approach. Antioxidants 2021, 10, 1753. https:// doi.org/10.3390/antiox10111753

Academic Editors: Julia Kuligowski and Máximo Vento

Received: 1 October 2021

Accepted: 29 October 2021

Published: 2 November 2021

Publisher's Note: MDPI stays neutral with regard to jurisdictional claims in published maps and institutional affiliations.

Copyright: () 2021 by the authors. Licensee MDPI, Basel, Switzerland. This article is an open access article distributed under the terms and conditions of the Creative Commons Attribution (CC BY) license (https:// creativecommons.org/licenses/by/ $4.0 /)$.

\begin{abstract}
There is a need for feasible and non-invasive diagnostics in perinatal asphyxia. Metabolomics is the study of small molecular weight products of cellular metabolism that may, directly and indirectly, reflect the level of oxidative stress. Saliva analysis is a novel approach that has a yet unexplored potential in metabolomics in perinatal asphyxia. The aim of this review was to give an overview of metabolomics studies of oxidative stress in perinatal asphyxia, particularly searching for studies analyzing non-invasively collected biofluids including saliva. We searched the databases PubMed/Medline and included 11 original human and 4 animal studies. In perinatal asphyxia, whole blood, plasma, and urine are the most frequently used biofluids used for metabolomics analyses. Although changes in oxidative stress-related salivary metabolites have been reported in adults, the utility of this approach in perinatal asphyxia has not yet been explored. Human and animal studies indicate that, in addition to antioxidant enzymes, succinate and hypoxanthine, as well acylcarnitines may have discriminatory diagnostic and prognostic properties in perinatal asphyxia. Researchers may utilize the accumulating evidence of discriminatory metabolic patterns in perinatal asphyxia to develop bedside methods to measure oxidative stress metabolites in perinatal asphyxia. Although only supported by indirect evidence, saliva might be a candidate biofluid for such point-of-care diagnostics.
\end{abstract}

Keywords: asphyxia neonatorum; non-invasive diagnostics; metabolomics; oxidative stress; saliva

\section{Introduction}

Failed placental gas exchange or deficient gas exchange in the lungs after birth may cause perinatal asphyxia with hypoxia and hypercapnia resulting in mixed metabolic and respiratory acidosis. Asphyxiated infants can present with severe cardiorespiratory compromise at birth and a need for cardiopulmonary resuscitation with supplementary oxygen. However, mild symptoms of asphyxia may also result in later morbidity and mortality in affected infants [1,2].

In perinatal asphyxia, balancing the harmful effects of iatrogenic hyperoxia ('oxidative stress') vs. anaerobic metabolism (continuing/prolonged hypoxia) is a complex task. Although humans have physiological and biochemical defense mechanisms to prevent hypoxia [3], defense mechanisms against hyperoxia are less developed in newborn infants, with the resulting oxidative stress potentially causing organ injury.

During asphyxia and resuscitation, disrupted cellular homeostasis causes significant metabolic changes [4], and studies of the metabolome may provide a pathophysiological 'snapshot' of the condition. Metabolomics is the study of small molecular weight (<1500 Da) 
endogenous metabolites present in tissues or biofluids typically at concentrations above $1 \mathrm{uM}$, and may be used to directly and indirectly measure oxidative stress [5]. Measuring oxidative stress in the neonate could aid decisions to initiate time-critical interventions including therapeutic hypothermia but poses challenges due to difficult sampling as well as a need for quick and repeated analyses [6].

\section{Saliva as a Promising Simple and Non-Invasively Collected Biofluid}

In the search for therapeutic target molecules, saliva has been used as a matrix in genomics [7], proteomics [8], and metabolomics [9]. Non-invasive and safe real-time sampling, and ease of collection, handling, storage, and post-storage contribute to its attractiveness and relatively low costs. However, different collection methods might yield different analysis results. Thus, it is important to standardize the collection, e.g., either by passive drainage or by specific collection devices [8]. In newborn infants, saliva may have particular advantages over invasively collected biofluids including blood. Compared to blood sampling, saliva sampling is not painful and does not deplete patients with blood cells and nutrients.

The aim of this review paper is to provide an overview of metabolomics studies of oxidative stress in perinatal asphyxia, with particular emphasis on analysis methods and biofluids used. Measuring the level of oxidative stress might aid in diagnosing infants with significant perinatal asphyxia but a mild initial clinical presentation. We were particularly interested in evidence about feasible and non-invasive diagnostics, with saliva being a novel biofluid with yet unknown potential in perinatal asphyxia.

\section{Materials and Methods}

\section{Search Strategy and Selection Criteria}

We did a non-systematic search in PubMed/Medline with no limits on publication date. The search was finished in September 2021 and included the terms "metabolomics" AND "oxidative stress" AND "neonatal asphyxia" OR "perinatal asphyxia" OR "HIE" OR "hypoxic ischemic encephalopathy". Reference lists of relevant articles were hand searched for additional publications of interest. Only English-language, peer-reviewed studies were included. We excluded studies that analyzed oxidative stress in tissues, metabolomics studies with a lack of focus on oxidative stress, as well as review articles, case reports, and conference abstracts. We included studies in term and preterm infants, as well as animal studies. The search identified 11 original human studies and 4 original animal studies.

\section{Results}

\subsection{Methods for Metabolomics Analyses}

Metabolomics analyses can be targeted and untargeted [10], the latter investigating both known and unknown metabolites. Analytical methods for determination of small molecular weight metabolites in biofluids include (i) immunological methods including radioimmunoassay and enzyme-linked immunosorbent assay (targeted), (ii) high-resolution ${ }^{1} \mathrm{H}$ (proton) and ${ }^{13} \mathrm{C}$ nuclear magnetic resonance (NMR) spectroscopy [11] (targeted and untargeted), (iii) gas chromatography (GC) coupled to mass spectrometry (MS) (targeted and untargeted), (iv) (ultra-performance) liquid chromatography coupled to MS (LC-MS) (targeted and untargeted), (v) infrared and Raman spectroscopy [12,13], and (vi) capillary electrophoresis-time-of-flight mass spectrometry (CE-TOFMS) (semi-targeted).

MS-based assays are considered more accurate than immunological methods (Table 1), with LC-MS having advantages over GC-MS as it does not require as long derivatization processes that may cause measurement error. Moreover, ultra-high performance (UP) liquid chromatography tandem mass spectrometry (UPLC-MS/MS) enables rapid chromatographic separations. UPLC-MS/MS is characterized by good selectivity and sensitivity, and a high sample throughput [6]. The metabolomics MS-workflow for biofluids including saliva is presented in Figure 1. 
Table 1. Advantages and disadvantages of mass spectrometry-based assays and immunoassays [14].

\begin{tabular}{|c|c|c|}
\hline Method & Advantages & Disadvantages \\
\hline \multirow[t]{8}{*}{ Mass spectrometry } & High selectivity & Limited to some laboratories \\
\hline & High sensitivity & Limited sample throughput \\
\hline & High throughput & Limited user friendliness, requires specialized personnel \\
\hline & Requires low sample volumes & High equipment costs \\
\hline & Multiplexing possible & Sample complexity issues \\
\hline & Relatively low running costs & \\
\hline & Not restricted to biomolecules & \\
\hline & High intra- and inter-assay reproducibility & \\
\hline \multirow[t]{6}{*}{ Immunoassay } & Low training requirements & Limited selectivity \\
\hline & Kits available from commercial vendors & Limited analyte detection abilities \\
\hline & Validated and approved & Requires relatively high sample volumes \\
\hline & Relatively low-cost equipment & Relatively expensive reagents \\
\hline & Relatively high throughput & $\begin{array}{l}\text { Relatively high intra- and interassay and laboratory } \\
\text { variability }\end{array}$ \\
\hline & Relatively high sensitivity & Relatively long assay time \\
\hline
\end{tabular}

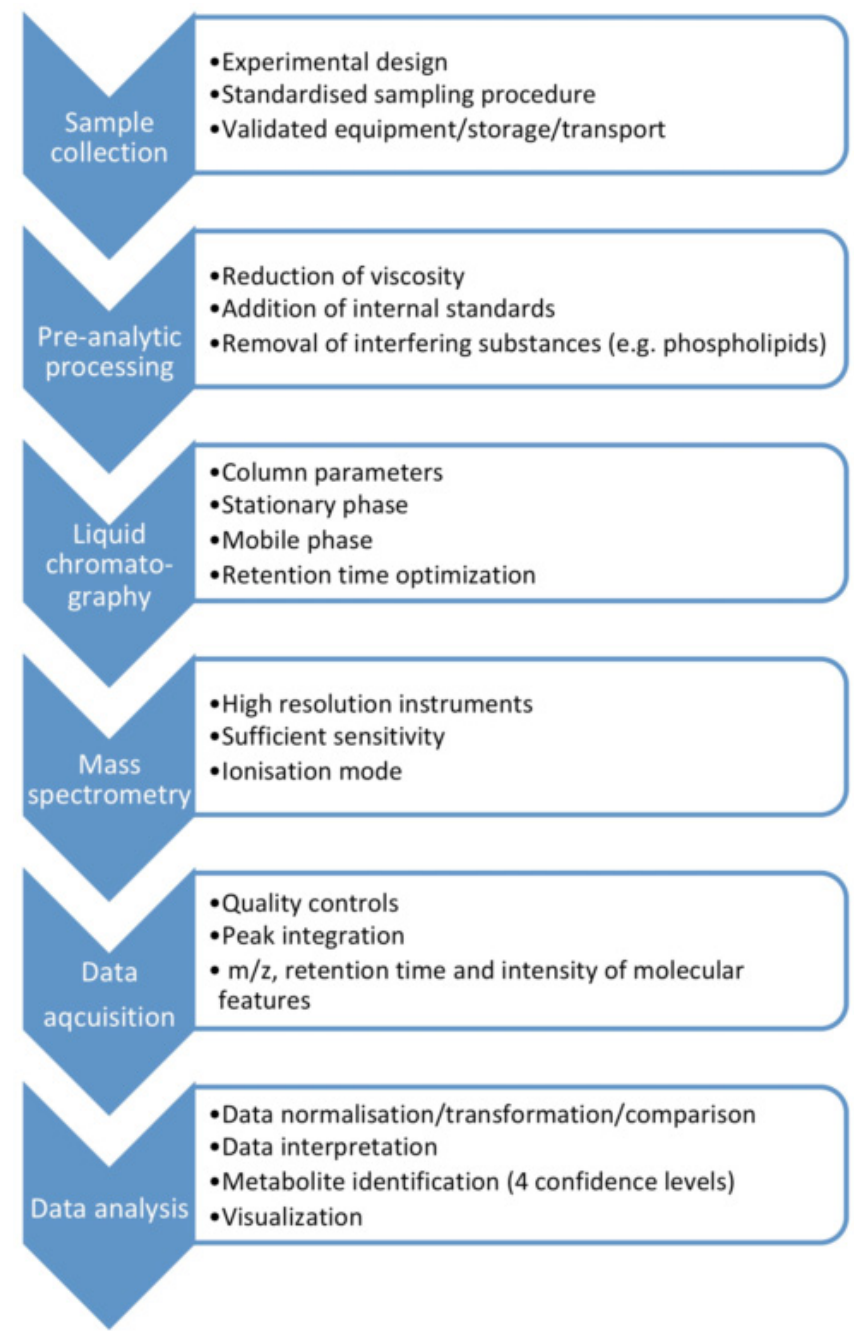

Figure 1. The metabolomics mass spectrometry workflow for biofluids including saliva. 


\subsection{Different Biofluids}

\subsubsection{Blood}

Blood is the biological material for most diagnostic tests in clinical routine. Blood reflects the dynamic, real-time metabolic response to asphyxia and reoxygenation, and allows for quick analysis. However, blood sampling in neonates may be technically challenging, is invasive, and painful. Blood sampling may contribute to anemia in more premature infants as their blood volume is lower. Indeed, Sachse et al. [11] were able to perform ${ }^{1} \mathrm{H}$ NMR metabolomics analysis with only $250 \mu \mathrm{L}$ of piglet plasma, and SanchezIllana et al. [6] used $100 \mu \mathrm{L}$ plasma for UPLC-MS/MS analysis. Dekker et al. [15] used $300 \mu \mathrm{L}$ full blood from premature infants.

An alternative blood sample option is umbilical cord blood, which is non-invasive and painless and may allow the collection of larger volumes to perform several analyses. However, umbilical cord blood only provides information until the time of birth. Thus, combined measurements of metabolites in umbilical cord blood and subsequently in the infant's blood are needed.

There is increasing evidence that preanalytical factors may heavily influence the results in metabolomics, both in the individual investigated and handling of the sample before metabolomic analyses. Currently, the need for access to advanced sample preparation is needed when conducting metabolomic studies [16]. Dried blood spot samples have been suggested for metabolomics analysis as they do not require preanalytical preparation, special storage, or freezing [17]. Several studies indicate the utility of blood spots for metabolomics analysis, with dried blood spots being largely equivalent to proteinprecipitated plasma $[18,19]$.

\subsubsection{Urine}

Although urine collection might be an easy alternative, the urine output in the first days after birth is typically low, and infants with perinatal asphyxia often have impaired renal function with oliguria or anuria. Urine for metabolomics analysis must be collected under sterile conditions because bacterial metabolism influences the urine metabolome, and samples must be frozen at $-80^{\circ} \mathrm{C}$ immediately after collection [20]. Urine is suitable for repeat analysis and assessment of markers of lipid peroxidation up to days or weeks after an insult or intervention, with the associated disadvantage of limited time resolution. Thus, urine analysis might not be the preferred option when the purpose is to institute time-critical interventions.

Sachse et al. [11] used $550 \mu \mathrm{L}$ of piglet urine for ${ }^{1} \mathrm{H}$ NMR metabolomics analysis. They demonstrated a different time profile of plasma versus urine metabolites and concluded that renal handling of different metabolites may vary and needs to be considered if urine is used instead of plasma in metabolomic analyses.

\subsubsection{Cerebrospinal Fluid}

Cerebrospinal fluid (CSF) is used in the diagnosis and management of neurological diseases. CSF is produced by plasma ultrafiltration and membrane secretion, is nearly free from cells, and protein levels are usually very low. However, CSF must be collected through a lumbar puncture, which is invasive and may be technically difficult in neonates. The quantity of fluid obtained may be limited and hemorrhage caused by the puncture may preclude interpretation. Thus, CSF metabolomics analyses have been performed in the experimental [21], but only rarely in the clinical setting of perinatal asphyxia [22].

\subsubsection{Saliva}

Although saliva can be collected non-invasively, the quantity may be limited. However, technological advances enable the analysis of small sample volumes (Table 2). Yen et al. [23] state that suctioning of the mouth typically yields $10-50 \mu \mathrm{L}$ neonatal saliva, whereas sponges and wick applicators may yield slightly higher volumes, directly correlated to collection time. Oxidative stress markers glutathione [24], malondialdehyde [24-27] catalase, 
protein carbonyls, glutathione peroxidase, and 8-hydroxy-2'-deoxyguanosine [27], as well as isoprotanes, isofuranes, neuroprostanes, and neurofuranes [28] have all been measured in saliva from adults. However, although sporadically mentioned as an alternative [5,29], the evidence of metabolomics analysis of saliva in asphyxiated neonates is sparse, if not non-existing.

A selection of metabolites related to oxidative stress is presented in Table 2.

Table 2. Metabolites related to oxidative stress [29-32]. Reproduced with permission from Dr. Wishart, University of Alberta, Edmonton, Canada.

\begin{tabular}{ll}
\hline Metabolite & Description \\
\hline Urea & The principal end product of protein catabolism. \\
\hline Creatinine & A breakdown product of creatine phosphate in muscle. \\
\hline Malonic acid & $\begin{array}{l}\text { Malonic acid, also known as malonate or H2MALO, belongs to the class of organic compounds } \\
\text { known as dicarboxylic acids and derivatives. In humans, malonic acid is involved in fatty acid } \\
\text { biosynthesis }\end{array}$ \\
\hline Methylguanidine & $\begin{array}{l}\text { A guanidine compound deriving from protein catabolism. Synthesized from creatinine concomitant } \\
\text { with the synthesis of hydrogen peroxide from endogenous substrates in peroxisomes. A nitric oxide } \\
\text { synthase inhibitor. }\end{array}$
\end{tabular}

Alanine (Ala), also known as L-alanine, is an alpha-amino acid. Glutamate can transfer its amino

L-Alanine group to pyruvate, a product of muscle glycolysis, through the action of alanine aminotransferase, forming alanine and alpha-ketoglutarate. Plasma alanine is often decreased when branched chain amino acids (BCAA) are deficient.

\begin{tabular}{|c|c|}
\hline Succinate & Succinic acid (succinate) is a dicarboxylic acid. \\
\hline Fumaric acid & Fumaric acid is a dicarboxylic acid. \\
\hline Alpha-ketoglutarate & $\begin{array}{l}\text { Oxoglutaric acid, also known as alpha-ketoglutarate, alpha-ketoglutaric acid, AKG, or 2-oxoglutaric } \\
\text { acid. AKG is a nitrogen scavenger. }\end{array}$ \\
\hline Hydroxycholesterol & $\begin{array}{l}\text { 27-Hydroxycholesterol ( } 27-\mathrm{HC}) \text {, also known as ( } 25 \mathrm{R}) \text {-cholest- } 5 \text {-ene-3 } \beta, 26 \text {-diol or by its conventional } \\
\text { name } 26 \text {-hydroxycholesterol. }\end{array}$ \\
\hline S-Adenosylmethionine & $\begin{array}{l}\text { S-Adenosylmethionine, also known as SAM or acylcarnitine, belongs to the class of organic } \\
\text { compounds known as 5'-deoxy-5'-thionucleosides. Possesses anti-inflammatory activity. }\end{array}$ \\
\hline Glycine & $\begin{array}{l}\text { An alpha-amino acid. Glycine is involved in the body's production of DNA, hemoglobin, and } \\
\text { collagen, and in the release of energy. }\end{array}$ \\
\hline Hypoxanthine & $\begin{array}{l}\text { Hypoxanthine, also known as purine-6-ol or Hyp, belongs to the class of organic compounds known } \\
\text { as purines. Under normal circumstances hypoxanthine is readily converted to uric acid. }\end{array}$ \\
\hline Valine & $\begin{array}{l}\text { Valine (Val) or L-valine is an alpha-amino acid. L-valine is a BCAA. The BCAAs consist of leucine, } \\
\text { valine, and isoleucine (and occasionally threonine). }\end{array}$ \\
\hline Choline & $\begin{array}{l}\text { Important as a precursor of acetylcholine, as a methyl donor in various metabolic processes, and in } \\
\text { lipid metabolism. }\end{array}$ \\
\hline Glutathione & Like cysteine, glutathione contains the crucial thiol (-SH) group that makes it an effective antioxidant. \\
\hline Ethylmalonate & $\begin{array}{l}\text { Ethylmalonic acid, also known as alpha-carboxybutyric acid or ethylmalonate, is a branched fatty } \\
\text { acid. Ethylmalonic acid can be synthesized from malonic acid. }\end{array}$ \\
\hline $\begin{array}{l}\text { 3-Hydroxymethylglutaric } \\
\text { acid }\end{array}$ & 3-Hydroxymethylglutaric acid is an "off-product" intermediate in the leucine degradation process. \\
\hline Glutaric acid & Is produced during the metabolism of some amino acids, including lysine and tryptophan. \\
\hline Methylmalonic acid & $\begin{array}{l}\text { Methylmalonic acid is a malonic acid derivative, which is a vital intermediate in the metabolism of } \\
\text { fat and protein. }\end{array}$ \\
\hline
\end{tabular}


Table 2. Cont.

\begin{tabular}{ll}
\hline Metabolite & Description \\
\hline Threonine & $\begin{array}{l}\text { Threonine (Thr) or L-threonine is an alpha-amino acid. Threonine is sometimes considered a BCAA. } \\
\text { Threonine is metabolized in at least two ways. In many animals it is converted to pyruvate via } \\
\text { threonine dehydrogenase. An intermediate in this pathway can undergo thiolysis with CoA to } \\
\text { produce acetyl-CoA and glycine. }\end{array}$ \\
\hline 3-Hydroxyisovaleric acid & A byproduct of the leucine degradation pathway. \\
\hline Dimethylglycine & $\begin{array}{l}\text { Dimethylglycine (DMG) is an amino acid derivative. The human body produces DMG when } \\
\text { metabolizing choline into glycine. Homocysteine and betaine are converted to methionine and } \\
\text { N,N-dimethylglycine by betaine-homocysteine methyltransferase. }\end{array}$ \\
\hline Dimethylamine & $\begin{array}{l}\text { An organic secondary amine. } \\
\text { Areatine }\end{array}$ \\
\hline $\begin{array}{l}\text { primary metabolic role is to combine with a phosphoryl group, via the enzyme creatine kinase, to } \\
\text { generate phosphocreatine, which is used to regenerate ATP. It is naturally produced in the human } \\
\text { body from the amino acids glycine and arginine, with an additional requirement for methionine to } \\
\text { catalyze the transformation of guanidinoacetate to creatine. }\end{array}$ \\
$\begin{array}{l}\text { The simplest carboxylic acid. Inhibition of cytochrome oxidase by formate may cause cell death by } \\
\text { increased production of cytotoxic reactive oxygen species secondary to the blockade of the electron } \\
\text { transport chain). }\end{array}$ \\
\hline
\end{tabular}

\subsection{Animal Studies}

In animal models of perinatal asphyxia, 100\% oxygen was associated with metabolic markers of delayed cellular recovery and increased oxidative stress [30-32]:

In a piglet model of perinatal asphyxia, baseline urine metabolome, analyzed with ${ }^{1} \mathrm{H}$ NMR spectroscopy, distinguished between piglets that later became asystolic or not. The post-resuscitation-, seen in relation to the baseline metabolome, differentiated between piglets reoxygenated with different oxygen concentrations, primarily due to variations in metabolites with free radical scavenging properties: urea, creatinine, and malonate, as well as methylguanidine and hydroxyisobutyric acid [31]. A few years later, the same group investigated the same oxygen concentrations and confirmed distinct urine metabolomic patterns in piglets reoxygenated with $18,21,40$, and $100 \%$ oxygen, respectively. Alanine and succinate were elevated, but glycine was unchanged in asphyxiated piglets resuscitated with $21 \%$ oxygen [32].

Moreover, in asphyxiated piglets and using flow injection analysis, MS/MS and LC-MS/MS, Solberg et al. [30] measured reduced blood succinate, fumarate, and alpha keto-glutarate indicating an earlier mitochondrial recovery when $21 \%$ oxygen was used for reoxygenation compared to $100 \%$ oxygen. Furthermore, oxysterols and acylcarnitine showed a differential response to $21 \%$ versus $100 \%$ oxygen reoxygenation. The ratios of alanine to branched chained amino acids, and of glycine to branched chained amino acids correlated with the duration of hypoxia.

Sachse et al. [11] reported a strong and consistent increase in alanine, succinate, hypoxanthine, and branched-chain amino acids in 125 asphyxiated piglets. There was a decrease of ${ }^{1} \mathrm{H}$ NMR signals associated with lipids. Baseline plasma hypoxanthine and lipoprotein concentrations were inversely correlated to the duration of hypoxia sustained before asystole occurred, but there was no evidence for a differential metabolic response to different resuscitation protocols including the use of supplementary oxygen, or in terms of survival [11]. In urine, branched-chain amino acids, especially valine, but also alanine and choline concentrations were higher after asphyxia and resuscitation compared to baseline.

\subsection{Clinical Studies}

Studies have comprehensively examined the metabolome in hypoxic-ischemic encephalopathy (HIE), but with a minor focus on oxygenation and oxidative stress [33,34]. A study of initial ventilation with $30 \%$ vs. $90 \%$ oxygen provided insights into oxidative stress 
markers in blood and urine of preterm infants $\leq 28$ weeks of gestation, but not related to perinatal asphyxia [35].

\subsubsection{Response to Hyperoxia}

Vento et al. [36-39], showed that the blood reduced (GSH)-to-oxidized glutathione (GSSG) ratio was lower in asphyxiated infants that received $100 \%$ oxygen compared to $21 \%$ oxygen, lasting up to four weeks after birth [37]. Hundred percent oxygen ventilation was associated with increased activity of antioxidant enzymes including superoxide dismutase and glutathione redox cycle enzymes [38,39]. Urine N-acetyl-glucosaminidase correlated with GSSG and was significantly higher in infants that received 100\% oxygen [36].

Dekker et al. [15] recently investigated initial ventilation with $30 \%$ versus $100 \%$ oxygen in preterm infants $<30$ weeks' gestation and found no difference in the lipid peroxidation product 8-iso-prostaglandin in umbilical cord blood, or infant blood at 1 and 24 h of age between $0 \%$ versus $100 \%$ oxygen.

\subsubsection{Prognostic Utility}

Negro et al. [40] measured blood advanced oxidation protein products (AOPP), nonprotein bound iron (NPBI), and F2-isoprostanes (F2-IsoPs) in 84 infants with severe versus mild/moderate HIE at three different time points: P1 (4-6 h), P2 (24-72 h), and P3 (5 days). Mean (standard deviation) values of AOPP, NPBI, but not F2-IsoPs were significantly higher in infants with severe HIE with AOPP 34.1(39.2) vs. 15.7(15.5), $p=0.033$ and NPBI 3.9 (4.4) versus 1.1(2.5), $p=0.013$ at P1. However, there was no difference between groups at P2 and P3. A regression model showed that AOPP levels and male sex were both risk factors for higher brain damage scores; AOPP: OR 3.6, 95\% confidence interval (1.1-12.2) and sex: OR 5.6, 95\% confidence interval (1.2-25.7), respectively.

Vasiljevic et al. [22] performed routine lumbar puncture in 90 infants with HIE and reported a good relationship of glutathione peroxidase activity with the clinical stage of HIE $(p<0.0001)$ and gestational age $(p<0.0001)$. Glutathione peroxidase activity in CSF corresponded to later neurodevelopment outcome $(p<0.001)$ and showed a strong correlation with CSF levels of neuron-specific enolase $(p<0.001)$, a biomarker of the extent of brain injury.

Umbilical cord blood from term infants with confirmed HIE $(n=31)$ was compared to asphyxiated infants without encephalopathy $(n=40)$, and matched controls $(n=71)$ [41] Targeted metabolomics revealed a significant increase in 29 metabolites from 3 distinct classes (amino acids, acylcarnitines, and glycerophospholipids) in infants with HIE or asphyxia compared to controls. Moreover, eight amino acids significantly increased in infants with HIE, but not asphyxia or matched controls. Thirteen acylcarnitines were significantly increased in infants with HIE and asphyxia without HIE, but the changes were more pronounced in the HIE population. A logistic regression model using five metabolites clearly delineated the severity of asphyxia and classified HIE infants with AUC $=0.92$. These data suggest significant disruption to the energy pathways as well as nitrogen and lipid metabolism in both asphyxia and HIE.

Chu et al. [42] analyzed urine metabolite profiles from 256 asphyxiated infants and reported a positive relationship between suppressed biochemical networks involved in the macromolecular synthesis and perinatal asphyxia associated with significant oxidative stress and morbidity. In particular, elevated organic acids related to oxidative stress were significantly associated with neurodevelopmental outcomes: Ethylmalonate, 3-hydroxy3-methylglutarate, 2-hydroxy-glutarate and 2-oxo-glutarate were associated with a good outcome; whereas glutarate, methylmalonate, 3-hydroxy-butyrate, and orotate were associated with a poor outcome. In preterm asphyxiated infants, urine threonine and 3hydroxyisovalerate were increased; and dimethylglycine, dimethylamine, creatine, succinate, formate, urea, and aconitate were decreased [43]. These data demonstrated the potential application of bioinformatics methods in this metabolomics study and its potential clinical relevance. 
Reinke et al. [44] proposed a metabolomic index ((succinate $x$ glycerol) / ( $\beta$-hydroxybutyrate $\times$ O-phosphocholine)) to identify asphyxiated infants at risk of developing HIE, as elevated $\beta$-hydroxybutyrate, glycerol, O-phosphocholine, and succinate were most strongly associated with HIE severity. Ahearne et al. [45] later showed that if this index was $<0.13$, the outcome was likely to be normal (sensitivity $65 \%$ and specificity of $91 \%$ ), whereas an index $>2.4$ was associated with a "severe outcome" (sensitivity of $80 \%$ and specificity of $100 \%$ ). The authors concluded that this metabolomic index might be used in identifying neonates at risk of developing severe HIE.

\section{Discussion}

With a focus on oxidative stress, human and animal studies indicate that Krebs cycle intermediates including succinate, and hypoxanthine, in addition to acylcarnitines, play a role in perinatal asphyxia and may have prognostic and discriminatory properties.

The neonatal brain is highly oxygen dependent with low antioxidant capacity. This, combined with a high content of unsaturated fatty acids, makes the neonatal brain particularly vulnerable to oxidative stress [46]. Hypoxanthine is a purine metabolite, and levels are elevated during hypoxia. Hypoxanthine is oxidized in the presence of xanthine oxidase to uric acid during reoxygenation [47]. This generates an oxygen-free radical burst that, although uric acid has antioxidant properties, overwhelms endogenous antioxidant defense systems. Excessive production of reactive oxygen species [48] including hydrogen peroxide, hydroxyl free radical, superoxide anion radical, and reactive nitrogen species [49], proteases and caspases [50] in turn cause mitochondrial dysfunction and cell death. Free radical-induced lipid (arachidonic acid) peroxidation results in the generation of prostaglandin-like (prostanoids) isoprostanes [51,52]. Isoprostanes are often considered the gold standard for in vivo measurement of lipid peroxidation [53-55]. However, biofluid isoprostanes have demonstrated limited discriminatory properties in asphyxiated infants.

In asphyxia, incomplete fatty acid oxidation may result in an increase of fatty acid coenzyme A esters which bind to carnitine, resulting in the production of acylcarnitines [56]. High carnitine suppresses lipid peroxidation and the production of hydroxyl free radicals [57]. Carnitine thus has potent antioxidant activity [58], whereas acylcarnitines in perinatal asphyxia may indirectly reflect oxidative stress. Superoxide dismutase, glutathione, catalase, and glutathione peroxidase are cellular antioxidants [49]. Debuf et al. [29] performed a review of biomarkers of perinatal asphyxia and highlighted acylcarnitines as the most promising.

Several reviews, including one very recent [29], have addressed metabolomics biomarker analysis in perinatal asphyxia and HIE. However, they did not focus on oxidative stress the way our present review does. Perinatal asphyxia is associated with increased metabolites derived from lipid peroxidation. However, lipid peroxidation products seem to have limited utility in identifying infants at risk of developing HIE. Therefore, it has been proposed that the most reliable way to use metabolomics in perinatal asphyxia risk stratification and prognostication, is the establishment of a metabolic index composed of multiple metabolites that together have better prognostic value.

Biomarkers used for screening should be easy to collect, have a fast laboratory turnaround time, be reliable, and relatively inexpensive. Modern methods, e.g., LCMS/MS have a turnaround time ranging from minutes to hours, opening for the possibility of integration into care. As stated by Debuf et al. [29], despite a current lack of pointof-care methods to measure these metabolites, considering the increasing advances in metabolomics, a "bench to the bedside" approach may be realistic within a reasonable time frame. Mussap et al. [5] suggested the translation of research results into the development of a low-cost device, e.g., a dipstick.

UPLC-MS/MS has been used to measure oxidative stress markers in saliva from adult patients and, although not supported by the available literature, saliva might be a suitable biofluid for point-of-care diagnostics. Saliva is, in theory, easy to collect and collection is non-invasive. However, saliva collection in newborns could be challenging, partially due 
to the limited amounts acquired. Standardized approaches to saliva collection, processing, and analyses are required for proper interpretation.

Strengths of this review include the innovative way of using existing knowledge to provide directions for research to develop non-invasive rapid tests of oxidative stress in perinatal asphyxia. Limitations include that we identified and report markers of oxidative stress in a wider sense and that we use indirect evidence, i.e., animal and adult data, to support our conclusions. However, we believe that the transparency of the reporting of results also leaves room for the readers to conclude from the limited knowledge base themselves.

In conclusion, in perinatal asphyxia, evidence about discriminatory metabolites related to oxidative stress, single or in combination, could be used to develop methods for rapid diagnostic and risk assessment purposes. Saliva might be a candidate biofluid for such point-of-care methods, however, more research is needed.

Author Contributions: A.L.S., S.N.Z., P.M.T. and G.M.S. performed data analysis and interpretation and drafted the initial version of the manuscript. All authors participated in critical revision of the manuscript for important intellectual content. All authors have read and agreed to the published version of the manuscript.

Funding: This research received no external funding.

Conflicts of Interest: The authors declare that the research was conducted in the absence of any commercial or financial relationships that could be construed as a potential conflict of interest.

\section{References}

1. DuPont, T.L.; Chalak, L.F.; Morriss, M.C.; Burchfield, P.J.; Christie, L.; Sanchez, P.J. Short-term outcomes of newborns with perinatal acidemia who are not eligible for systemic hypothermia therapy. J. Pediatrics 2013, 162, 35-41. [CrossRef] [PubMed]

2. Odd, D.E.; Lewis, G.; Whitelaw, A.; Gunnell, D. Resuscitation at birth and cognition at 8 years of age: A cohort study. Lancet 2009, 373, 1615-1622. [CrossRef]

3. Saugstad, O.D.; Oei, J.L.; Lakshminrusimha, S.; Vento, M. Oxygen therapy of the newborn from molecular understanding to clinical practice. Pediatric Res. 2019, 85, 20-29. [CrossRef]

4. Chalkias, A.; Fanos, V.; Noto, A.; Castren, M.; Gulati, A.; Svavarsdottir, H.; Iacovidou, N.; Xanthos, T. 1H NMR-metabolomics: Can they be a useful tool in our understanding of cardiac arrest? Resuscitation 2014, 85, 595-601. [CrossRef]

5. Mussap, M.; Antonucci, R.; Noto, A.; Fanos, V. The role of metabolomics in neonatal and pediatric laboratory medicine. Clin. Chim. Acta 2013, 426, 127-138. [CrossRef] [PubMed]

6. Sanchez-Illana, A.; Thayyil, S.; Montaldo, P.; Jenkins, D.; Quintas, G.; Oger, C.; Galano, J.M.; Vigor, C.; Durand, T.; Vento, M.; et al. Novel free-radical mediated lipid peroxidation biomarkers in newborn plasma. Anal. Chim. Acta 2017, 996, 88-97. [CrossRef] [PubMed]

7. Chattopadhyay, I.; Panda, M. Recent trends of saliva omics biomarkers for the diagnosis and treatment of oral cancer. J. Oral Biosci. 2019, 61, 84-94. [CrossRef]

8. Laputkova, G.; Schwartzova, V.; Banovcin, J.; Alexovic, M.; Sabo, J. Salivary Protein Roles in Oral Health and as Predictors of Caries Risk. Open Life Sci. 2018, 13, 174-200. [CrossRef] [PubMed]

9. Patil, D.J.; More, C.B. Salivary metabolomics-A diagnostic and biologic signature for oral cancer. J. Oral Maxillofac. Surg. Med. Pathol. 2021, 33, 546-554. [CrossRef]

10. Oldiges, M.; Lutz, S.; Pflug, S.; Schroer, K.; Stein, N.; Wiendahl, C. Metabolomics: Current state and evolving methodologies and tools. Appl. Microbiol. Biotechnol. 2007, 76, 495-511. [CrossRef]

11. Sachse, D.; Solevag, A.L.; Berg, J.P.; Nakstad, B. The Role of Plasma and Urine Metabolomics in Identifying New Biomarkers in Severe Newborn Asphyxia: A Study of Asphyxiated Newborn Pigs following Cardiopulmonary Resuscitation. PLoS ONE 2016, 11, e0161123. [CrossRef]

12. Ellis, D.I.; Goodacre, R. Metabolic fingerprinting in disease diagnosis: Biomedical applications of infrared and Raman spectroscopy. Analyst 2006, 131, 875-885. [CrossRef] [PubMed]

13. Krafft, C.; Steiner, G.; Beleites, C.; Salzer, R. Disease recognition by infrared and Raman spectroscopy. J. Biophotonics 2009, 2, 13-28. [CrossRef]

14. Cross, T.G.; Hornshaw, M.P. Can LC and LC-MS ever replace immunoassays? J. Appl. Bioanal. 2016, 2, 108-116. [CrossRef]

15. Dekker, J.; Martherus, T.; Lopriore, E.; Giera, M.; McGillick, E.V.; Hutten, J.; van Leuteren, R.W.; van Kaam, A.H.; Hooper, S.B.; Te Pas, A.B. The Effect of Initial High vs. Low FiO2 on Breathing Effort in Preterm Infants at Birth: A Randomized Controlled Trial. Front. Pediatr. 2019, 7, 504. [CrossRef] [PubMed]

16. Salvagno, G.L.; Danese, E.; Lippi, G. Preanalytical variables for liquid chromatography-mass spectrometry (LC-MS) analysis of human blood specimens. Clin. Biochem. 2017, 50, 582-586. [CrossRef] 
17. Kong, S.T.; Lin, H.S.; Ching, J.; Ho, P.C. Evaluation of dried blood spots as sample matrix for gas chromatography/mass spectrometry based metabolomic profiling. Anal. Chem. 2011, 83, 4314-4318. [CrossRef] [PubMed]

18. Wilson, I. Global metabolic profiling (metabonomics/metabolomics) using dried blood spots: Advantages and pitfalls. Bioanalysis 2011, 3, 2255-2257. [CrossRef]

19. Michopoulos, F.; Theodoridis, G.; Smith, C.J.; Wilson, I.D. Metabolite profiles from dried blood spots for metabonomic studies using UPLC combined with orthogonal acceleration ToF-MS: Effects of different papers and sample storage stability. Bioanalysis 2011, 3, 2757-2767. [CrossRef] [PubMed]

20. Gika, H.G.; Theodoridis, G.A.; Wilson, I.D. Liquid chromatography and ultra-performance liquid chromatography-mass spectrometry fingerprinting of human urine: Sample stability under different handling and storage conditions for metabonomics studies. J. Chromatogr. A 2008, 1189, 314-322. [CrossRef]

21. Ventrella, D.; Laghi, L.; Barone, F.; Elmi, A.; Romagnoli, N.; Bacci, M.L. Age-Related 1H NMR Characterization of Cerebrospinal Fluid in Newborn and Young Healthy Piglets. PLoS ONE 2016, 11, e0157623. [CrossRef]

22. Vasiljevic, B.; Maglajlic-Djukic, S.; Gojnic, M.; Stankovic, S. The role of oxidative stress in perinatal hypoxic-ischemic brain injury. Srp. Arh. za Celok. Lek. 2012, 140, 35-41. [CrossRef]

23. Yen, E.; Kaneko-Tarui, T.; Maron, J.L. Technical Considerations and Protocol Optimization for Neonatal Salivary Biomarker Discovery and Analysis. Front. Pediatr. 2020, 8, 618553. [CrossRef] [PubMed]

24. Metgud, R.; Bajaj, S. Evaluation of salivary and serum lipid peroxidation, and glutathione in oral leukoplakia and oral squamous cell carcinoma. J. Oral Sci. 2014, 56, 135-142. [CrossRef] [PubMed]

25. Baltacioglu, E.; Yuva, P.; Aydin, G.; Alver, A.; Kahraman, C.; Karabulut, E.; Akalin, F.A. Lipid peroxidation levels and total oxidant/antioxidant status in serum and saliva from patients with chronic and aggressive periodontitis. Oxidative stress index: A new biomarker for periodontal disease? J. Periodontol. 2014, 85, 1432-1441. [CrossRef] [PubMed]

26. Nguyen, T.T.; Ngo, L.Q.; Promsudthi, A.; Surarit, R. Salivary Lipid Peroxidation in Patients With Generalized Chronic Periodontitis and Acute Coronary Syndrome. J. Periodontol. 2016, 87, 134-141. [CrossRef]

27. Tarboush, N.A.; Al Masoodi, O.; Al Bdour, S.; Sawair, F.; Hassona, Y. Antioxidant capacity and biomarkers of oxidative stress in saliva of khat-chewing patients: A case-control study. Oral Surg. Oral Med. Oral Pathol. Oral Radiol. 2019, 127, 49-54. [CrossRef] [PubMed]

28. Pena-Bautista, C.; Carrascosa-Marco, P.; Oger, C.; Vigor, C.; Galano, J.M.; Durand, T.; Baquero, M.; Lopez-Nogueroles, M.; Vento, M.; Garcia-Blanco, A.; et al. Validated analytical method to determine new salivary lipid peroxidation compounds as potential neurodegenerative biomarkers. J. Pharm. Biomed. Anal. 2019, 164, 742-749. [CrossRef]

29. Debuf, M.J.; Carkeek, K.; Piersigilli, F. A Metabolomic Approach in Search of Neurobiomarkers of Perinatal Asphyxia: A Review of the Current Literature. Front. Pediatr. 2021, 9, 674585. [CrossRef]

30. Solberg, R.; Enot, D.; Deigner, H.P.; Koal, T.; Scholl-Burgi, S.; Saugstad, O.D.; Keller, M. Metabolomic analyses of plasma reveals new insights into asphyxia and resuscitation in pigs. PLoS ONE 2010, 5, e9606. [CrossRef]

31. Atzori, L.; Xanthos, T.; Barberini, L.; Antonucci, R.; Murgia, F.; Lussu, M.; Aroni, F.; Varsami, M.; Papalois, A.; Lai, A.; et al. A metabolomic approach in an experimental model of hypoxia-reoxygenation in newborn piglets: Urine predicts outcome. $J$. Matern. -Fetal Neonatal Med. 2010, 23 (Suppl. 3), 134-137. [CrossRef]

32. Fanos, V.; Noto, A.; Xanthos, T.; Lussu, M.; Murgia, F.; Barberini, L.; Finco, G.; d'Aloja, E.; Papalois, A.; Iacovidou, N.; et al Metabolomics network characterization of resuscitation after normocapnic hypoxia in a newborn piglet model supports the hypothesis that room air is better. BioMed Res. Int. 2014, 2014, 731620. [CrossRef]

33. Pineiro-Ramos, J.D.; Cascant, M.M.; Nunez-Ramiro, A.; Lopez-Gonzalvez, A.; Solaz-Garcia, A.; Albiach-Delgado, A.; MartinezRodilla, J.; Llorens-Salvador, R.; Sanjuan-Herraez, D.; Quintas, G.; et al. Noninvasive monitoring of evolving urinary metabolic patterns in neonatal encephalopathy. Pediatric Res. 2021, 127, 49-54. [CrossRef]

34. Pineiro-Ramos, J.D.; Nunez-Ramiro, A.; Llorens-Salvador, R.; Parra-Llorca, A.; Sanchez-Illana, A.; Quintas, G.; Boronat-Gonzalez, N.; Martinez-Rodilla, J.; Kuligowski, J.; Vento, M.; et al. Metabolic Phenotypes of Hypoxic-Ischemic Encephalopathy with Normal vs. Pathologic Magnetic Resonance Imaging Outcomes. Metabolites 2020, 10, 109. [CrossRef] [PubMed]

35. Vento, M.; Moro, M.; Escrig, R.; Arruza, L.; Villar, G.; Izquierdo, I.; Roberts, L.J.; Arduini, A.; Escobar, J.J.; Sastre, J.; et al. Preterm Resuscitation With Low Oxygen Causes Less Oxidative Stress, Inflammation, and Chronic Lung Disease. Pediatrics 2009, 124, e439-e449. [CrossRef]

36. Vento, M.; Sastre, J.; Asensi, M.A.; Vina, J. Room-air resuscitation causes less damage to heart and kidney than $100 \%$ oxygen. Am. J. Respir. Crit. Care Med. 2005, 172, 1393-1398. [CrossRef] [PubMed]

37. Vento, M.; Asensi, M.; Sastre, J.; Garcia-Sala, F.; Pallardo, F.V.; Vina, J. Resuscitation with Room Air Instead of $100 \%$ Oxygen Prevents Oxidative Stress in Moderately Asphyxiated Term Neonates. Pediatrics 2001, 107, 642-647. [CrossRef]

38. Vento, M.; Asensi, M.; Sastre, J.; Lloret, A.; Garcia-Sala, F.; Minana, J.B.; Vina, J. Hyperoxemia caused by resuscitation with pure oxygen may alter intracellular redox status by increasing oxidized glutathione in asphyxiated newly born infants. Semin. Perinatol. 2002, 26, 406-410. [CrossRef] [PubMed]

39. Vento, M.; Asensi, M.; Sastre, J.; Lloret, A.; Garça-Sala, F.; Viña, J. Oxidative stress in asphyxiated term infants resuscitated with 100\% oxygen. J. Pediatrics 2003, 142, 240-246. [CrossRef] 
40. Negro, S.; Benders, M.; Tataranno, M.L.; Coviello, C.; de Vries, L.S.; van Bel, F.; Groenendaal, F.; Longini, M.; Proietti, F.; Belvisi, E.; et al. Early Prediction of Hypoxic-Ischemic Brain Injury by a New Panel of Biomarkers in a Population of Term Newborns. Oxid. Med. Cell. Longev. 2018, 2018, 7608108. [CrossRef]

41. Walsh, B.H.; Broadhurst, D.I.; Mandal, R.; Wishart, D.S.; Boylan, G.B.; Kenny, L.C.; Murray, D.M. The metabolomic profile of umbilical cord blood in neonatal hypoxic ischaemic encephalopathy. PLoS ONE 2012, 7, e50520. [CrossRef] [PubMed]

42. Chu, C.Y.; Xiao, X.; Zhou, X.G.; Lau, T.K.; Rogers, M.S.; Fok, T.F.; Law, L.K.; Pang, C.P.; Wang, C.C. Metabolomic and bioinformatic analyses in asphyxiated neonates. Clin. Biochem. 2006, 39, 203-209. [CrossRef]

43. Longini, M.; Giglio, S.; Perrone, S.; Vivi, A.; Tassini, M.; Fanos, V.; Sarafidis, K.; Buonocore, G. Proton nuclear magnetic resonance spectroscopy of urine samples in preterm asphyctic newborn: A metabolomic approach. Clin. Chim. Acta 2015, 444, 250-256. [CrossRef]

44. Reinke, S.N.; Walsh, B.H.; Boylan, G.B.; Sykes, B.D.; Kenny, L.C.; Murray, D.M.; Broadhurst, D.I. 1H NMR derived metabolomic profile of neonatal asphyxia in umbilical cord serum: Implications for hypoxic ischemic encephalopathy. J. Proteome Res. 2013, 12, 4230-4239. [CrossRef]

45. Ahearne, C.E.; Denihan, N.M.; Walsh, B.H.; Reinke, S.N.; Kenny, L.C.; Boylan, G.B.; Broadhurst, D.I.; Murray, D.M. Early Cord Metabolite Index and Outcome in Perinatal Asphyxia and Hypoxic-Ischaemic Encephalopathy. Neonatology 2016, 110, $296-302$. [CrossRef]

46. Ferriero, D.M. Neonatal brain injury. N. Engl. J. Med. 2004, 351, 1985-1995. [CrossRef] [PubMed]

47. Saugstad, O.D. Hypoxanthine as an indicator of hypoxia: Its role in health and disease through free radical production. Pediatric Res. 1988, 23, 143-150. [CrossRef] [PubMed]

48. Li, J.; Gao, X.; Qian, M.; Eaton, J.W. Mitochondrial metabolism underlies hyperoxic cell damage. Free. Radic. Biol. Med. 2004, 36, 1460-1470. [CrossRef]

49. Liu, J.; Litt, L.; Segal, M.R.; Kelly, M.J.; Pelton, J.G.; Kim, M. Metabolomics of oxidative stress in recent studies of endogenous and exogenously administered intermediate metabolites. Int. J. Mol. Sci. 2011, 12, 6469-6501. [CrossRef]

50. Fatemi, A.; Wilson, M.A.; Johnston, M.V. Hypoxic-ischemic encephalopathy in the term infant. Clin. Perinatol. 2009, 36, 835-858. [CrossRef]

51. Morrow, J.D.; Hill, K.E.; Burk, R.F.; Nammour, T.M.; Badr, K.F.; Roberts, L.J., 2nd. A series of prostaglandin F2-like compounds are produced in vivo in humans by a non-cyclooxygenase, free radical-catalyzed mechanism. Proc. Natl. Acad. Sci. USA 1990, 87, 9383-9387. [CrossRef] [PubMed]

52. Milne, G.L.; Yin, H.; Morrow, J.D. Human biochemistry of the isoprostane pathway. J. Biol. Chem. 2008, 283, 15533-15537. [CrossRef] [PubMed]

53. Montine, K.S.; Quinn, J.F.; Zhang, J.; Fessel, J.P.; Roberts, L.J., 2nd; Morrow, J.D.; Montine, T.J. Isoprostanes and related products of lipid peroxidation in neurodegenerative diseases. Chem. Phys. Lipids 2004, 128, 117-124. [CrossRef]

54. Niki, E.; Yoshida, Y.; Saito, Y.; Noguchi, N. Lipid peroxidation: Mechanisms, inhibition, and biological effects. Biochem. Biophys. Res. Commun. 2005, 338, 668-676. [CrossRef] [PubMed]

55. Tsimikas, S. In vivo markers of oxidative stress and therapeutic interventions. Am. J. Cardiol. 2008, 101, 34D-42D. [CrossRef]

56. Rebouche, C.J. Kinetics, pharmacokinetics, and regulation of L-carnitine and acetyl-L-carnitine metabolism. Ann. N. Y. Acad Sci. 2004, 1033, 30-41. [CrossRef]

57. Oka, T.; Itoi, T.; Terada, N.; Nakanishi, H.; Taguchi, R.; Hamaoka, K. Change in the membranous lipid composition accelerates lipid peroxidation in young rat hearts subjected to 2 weeks of hypoxia followed by hyperoxia. Circ. J. 2008, 72, 1359-1366. [CrossRef]

58. Reznick, A.Z.; Kagan, V.E.; Ramsey, R.; Tsuchiya, M.; Khwaja, S.; Serbinova, E.A.; Packer, L. Antiradical effects in L-propionyl carnitine protection of the heart against ischemia-reperfusion injury: The possible role of iron chelation. Arch. Biochem. Biophys. 1992, 296, 394-401. [CrossRef] 